\title{
Exploring the use of dynamic linear panel data models for evaluating energy/economy/environment models - an application for the transportation sector
}

\author{
A. Schäfer $\cdot$ P. Kyle $\cdot$ R. Pietzcker
}

Received: 5 March 2013 / Accepted: 12 November 2014 /Published online: 25 November 2014

C The Author(s) 2014. This article is published with open access at Springerlink.com

\begin{abstract}
This paper uses the RoSE transportation sector scenarios of the GCAM and REMIND energy-economy-models for the U.S. region to derive and compare these models' intrinsic elasticities with those resulting from historical trends, estimates from the literature, and across each other. To estimate the model-intrinsic elasticities, we explore the use of dynamic linear panel data models. On the basis of 26 scenarios (panels) between 2010 and 2050, our analysis suggests that nearly all model-intrinsic elasticities with respect to final energy use are roughly comparable to each other, to those observed historically, and to those from other studies. The key difference is these models' comparatively low intrinsic income elasticity of final energy use. This and other minor differences are interpreted through key assumptions underlying both energy-economy-models.
\end{abstract}

\section{Introduction}

As economies develop and the value added shifts from agriculture to industry to services, energy use by and $\mathrm{CO}_{2}$ emissions from transportation continue to increase in both absolute and relative terms (see, e.g., Schäfer et al. 2009). Because of this rising importance, it is imperative to understand why long-term projections of this sector's energy use and $\mathrm{CO}_{2}$ emissions differ across models, and how these projections' underlying key characteristics compare to those observed historically.

This article is part of a Special Issue on "The Impact of Economic Growth and Fossil Fuel Availability on Climate Protection" with Guest Editors Elmar Kriegler, Ottmar Edenhofer, Ioanna Mouratiadou, Gunnar Luderer, and Jae Edmonds.

\footnotetext{
A. Schäfer $(\bowtie)$

UCL Energy Institute, University College London, London, UK

e-mail: a.schafer@ucl.ac.uk

A. Schäfer

Precourt Energy Efficiency Center, Stanford University, Stanford, USA

P. Kyle

Pacific Northwest Laboratory, Joint Global Change Research Institute, College Park, USA

R. Pietzcker

Potsdam Institute for Climate Impact Research, Potsdam, Germany
} 
The effort to compare and improve energy-economy-models has a long history. Stanford University's Energy Modeling Forum, which pursues these and related goals, already started in 1976 (EMF 1977). The usual approach has been to run the evaluated models under consistent assumptions of key determinants of energy use and associated $\mathrm{CO}_{2}$ emissions and then to systematically compare the outputs. Doing so, differences in model outputs are traced back to those of individual components, thus identifying key uncertainties with respect to model structure and chosen parameters. The RoSE project, to which this paper contributes, is one of many examples.

In this paper, we pursue an alternative approach by estimating and comparing the modelintrinsic elasticities across each other and with those of the historical trend. Varying the inputs into the energy-economy-models causes a responsiveness in the outputs. A sufficiently large number of scenarios with different model input assumptions (and therefore outputs) then constitutes a set of panels, which can be used to estimate the key aggregate characteristics of the underlying model. The obtained intrinsic elasticities account for the underlying model structure, embedded functional forms, assumptions about the substitutability of energy services, along technologies and their characteristics. This approach's advantage is that the estimated elasticities can be readily compared to each other, to those from the literature, and to those underlying the historical development, irrespective of the type of energy-economymodel examined. In addition, this approach does not depend on the use of identical assumptions of key determinants of energy use and associated $\mathrm{CO}_{2}$ emissions that serve as inputs into the models that are being compared. While there is a growing body of literature on validating energy-economy-models (Schwanitz 2013; Beckman et al. 2011; Wilson et al. 2013), we know of no research that would have taken our approach and compared model-intrinsic elasticities to each other and historic values.

We apply this approach to the transportation sector. Among the energy-economy-models used in the RoSE project, only GCAM and REMIND incorporate a transportation sector that is endogenously embedded within the energy economy. Although both models fall into the "hybrid energy models" category, they have important structural differences, which are likely to lead to different model outputs, despite consistent input assumptions with respect to economic growth, population, and the amount of fossil fuel resources.

This paper continues with describing the long-term historical and projected future trends in the U.S. transportation sector in terms of energy use, and its key determinants. Before specifying econometric models that allow estimating the historical elasticities and those intrinsic to the two energy-economy-models, the properties of the time series data need to be examined with respect to integrated processes that would render standard estimation techniques invalid. Thereafter we present the statistical models used to estimate the key elasticities that describe past trends in U.S. transport sector energy use and the projected levels from the GCAM and REMIND models. Then we interpret the results using the key features of the two energy models before summarizing and concluding this study's findings.

\section{Key characteristics of U.S. transportation energy use}

Figures 1a-d illustrate the historical and projected future levels of transport sector related final energy use, the weighted average consumer fuel prices, along key model inputs, i.e., GDP per person and population.

As depicted in Fig. 1a, between 1920 and 2010, final energy use in U.S. transportation multiplied by a factor of around 6 (Schäfer 2013). The model-projected future levels of transport sector final energy use differ widely, depending on the scenario. However, common to both model outputs is a strongly reduced future growth, an eventual leveling off and decline 

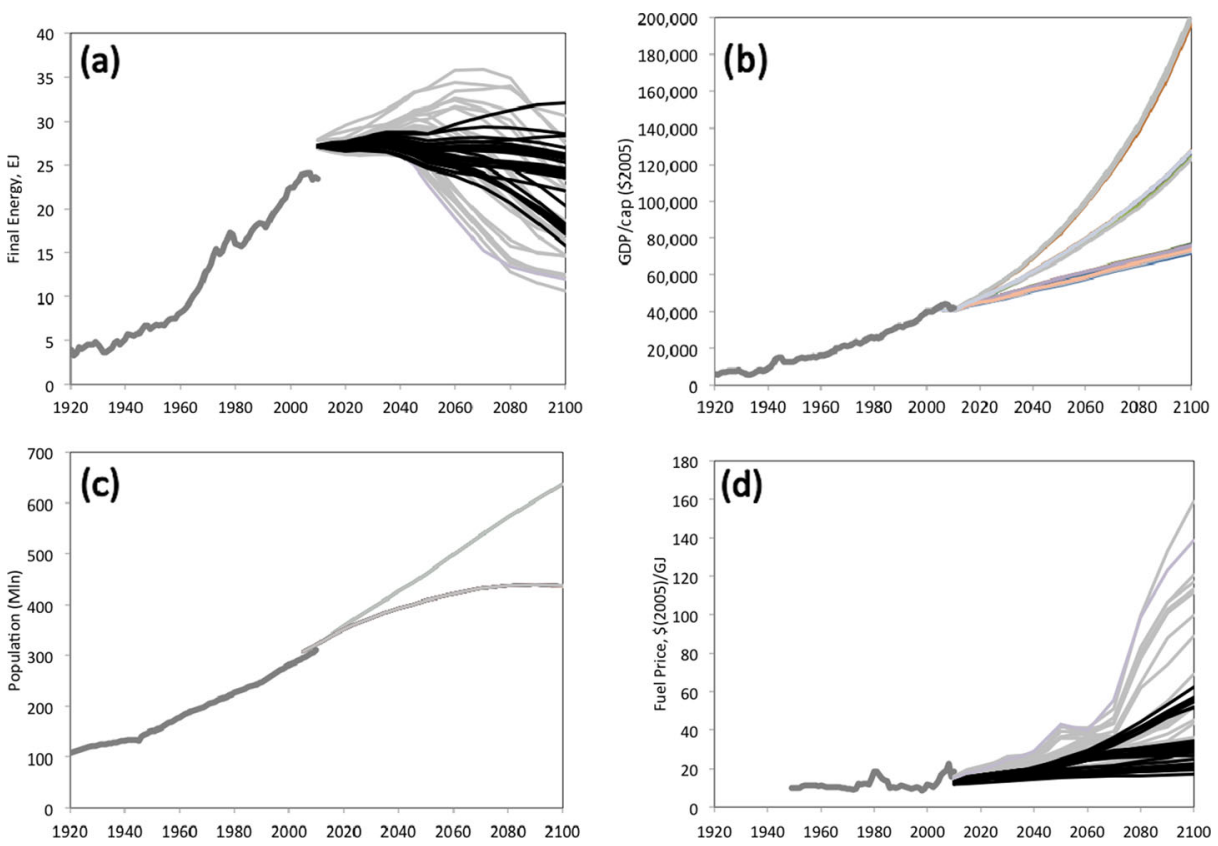

Fig. 1 Historical development and future projections of domestic U.S. transportation final energy use (a), GDP per person (b), population (c), and fuel prices (d) for REMIND (gray) and GCAM (black) scenarios

of final energy use, pointing to a lower income elasticity of final energy use than in the past. Thereby, REMIND outputs (gray trajectories) seem to experience a wider spread and larger income elasticity than those generated with GCAM (black trajectories). The gap between historical data and model outputs in 2010 can be attributed mainly to the U.S. portion of international marine shipping and aviation included in the GCAM and REMIND models. In addition, both GCAM and REMIND outputs include upstream energy use, which is excluded with the exception of those released during electricity generation in the historical data set (Schäfer 2013).

All future final energy use trajectories are based on three scenarios of GDP per capita (b), two population projections (c), and different assumptions about climate policy, ranging from no climate policy to atmospheric stabilization targets of 550 and $450 \mathrm{ppm} \mathrm{CO}_{2}$. The availability of fossil fuels and the size of a carbon tax under climate policies then determine the weighted average prices of transportation fuels (which here include carbon prices), which also differ widely between the two energy-economy-models (d). As with final energy use, the spread of REMIND prices (gray) is significantly larger compared to GCAM (black).

\section{Statistical properties of the underlying data}

The historical data encompasses the long-term development of final energy, per capita GDP, population (1920-2010), and (consumption-based) weighted average consumer fuel prices (1950-2010) on an annual basis. Before using these data for estimating statistical models, their basic characteristics need to be understood. Many types of economic time series data are integrated, that is, historical events have long-lasting impacts that alter the trajectory of a 
variable far into the future. Such non-stationary characteristics would make the coefficient and variance estimates meaningless. Therefore we conduct unit root or order of integration tests for the variables individually.

Figure 2 depicts the development of the four variables in terms of the natural logarithm of the levels (left column) and first differences (right column) for 61 years starting in 1950. The levels of the historical series in the left column in Fig. 2 appear non-stationary, i.e., have a unit root. In contrast, the first-differenced variables in the right column, with the exception of perhaps population, seem to be stationary. The first differences of the logarithms of final energy use appear to be trend stationary until the early 1970s and then stationary. Given the development of the levels of the variables of interest and that of the first differences, we added a trend term to the unit root tests for the variable in levels and a drift term when testing the first differences for unit roots.

The results of the unit root tests are shown in Table 1. The Augmented Dickey-Fuller (ADF) statistic of the underlying test of the historical time series data suggests clear evidence of a unit root in levels of all variables except the logarithm of population. (The null hypothesis is that the data series are non-stationary). However, first-differencing the data leads to stationary properties at a confidence level of at least $95 \%(* *$ in Table 1$)$ for all time series. Since all the series have a unit root and the order of integration is one, there may exist a statistical relation of the series in their levels that is stationary, suggesting cointegration.

As a basis for estimating the panel data models, we selected 26 scenarios that were simulated by both energy-economy-models. These scenarios can be classified in three families with internally consistent assumptions (Groups 1-3) and a fourth family with two remaining scenarios (Group 4). For a detailed description of the scenarios, see Kriegler et al. (this issue).

- Group 1: 8 baseline scenarios with different combinations of growth in income and population and the availability of fossil fuel resources (of which only the assumptions about the availability of oil are critical for the transportation sector)

- Group 2: 8 mitigation scenarios eventually leading to an atmospheric concentration of greenhouse gas emissions of $550 \mathrm{ppm}$ of $\mathrm{CO}_{2}$ equivalent

- Group 3: 8 mitigation scenarios eventually leading to an atmospheric concentration of greenhouse gas emissions of $450 \mathrm{ppm}$ of $\mathrm{CO}_{2}$ equivalent

- Group 4: 2 additional scenarios describing a moderate policy case and a scenario reaching $450 \mathrm{ppm} \mathrm{CO}_{2}$ equivalent by 2100 despite moderate policies until 2020

We also tested the GCAM and REMIND model outputs between 2010 and 2050, the period for which we obtained panel data with 5-year time steps, for unit roots. The employed ADF test rejected the null hypothesis that all panels would contain a unit root. As will be shown in Table 3 below, the elasticity of the lagged dependent variable is around 0.5 and thus far from unity, also eliminating any concern about the possible existence of unit roots. For brevity, we therefore do not report here the ADF test statistics of the model-derived panel data sets.

\section{Model specification}

The specification of our statistical models depends on the resolution of the two energyeconomy-models. In contrast to GCAM, the transportation sector in the REMIND version analyzed in this paper does not rigorously distinguish between passenger and freight transportation. Nor does it yield the demand for energy services (passenger-km traveled and tonne- 

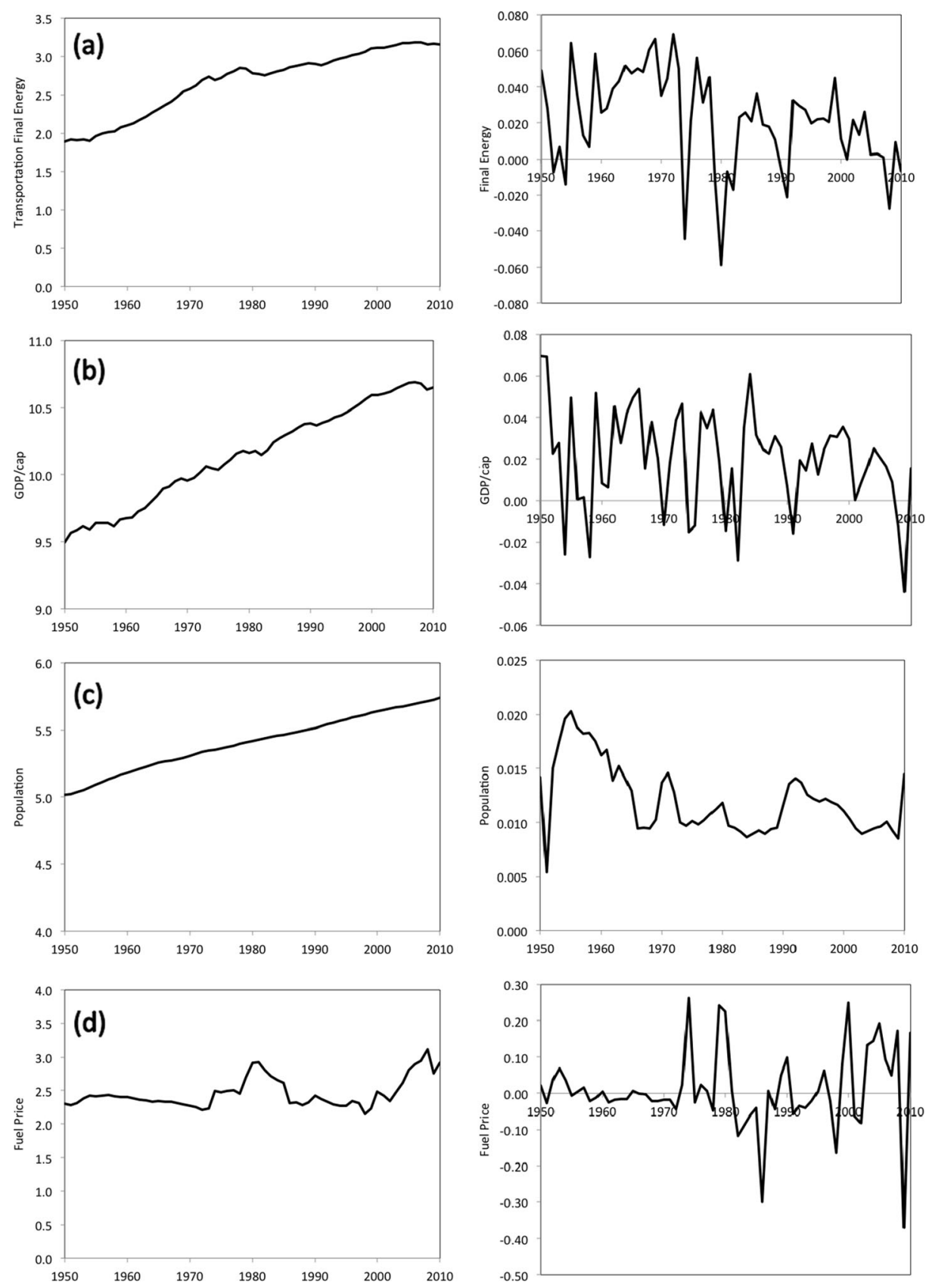

Fig. 2 Natural logarithm of historical domestic U.S. transportation sector final energy use (a), GDP per person (b), population (c), and fuel prices (d) in levels and first differences

kilometers generated). To enable comparability of the results, the statistical model needs to be specified in a way that is consistent with the less detailed structure of REMIND on the cost of heterogeneity. 
Table 1 Augmented Dickey-Fuller statistics for the variables in levels and first differences (FD), along with the lag length (in parenthesis) for the period 1950 to 2010

Test statistic

\begin{tabular}{lc} 
Ln FE & $-0.735(1)$ \\
Level & $-4.009(1)^{* * *}$ \\
FD & $-1.506(0)$ \\
Ln GDP/cap & $-6.968(0)^{* * *}$ \\
Level & $-3.534(1)^{* *}$ \\
FD & $-2.420(1)^{* * *}$ \\
Ln Pop & \\
Level & $-1.857(0)$ \\
FD & $-7.293(0)^{* * *}$ \\
Ln P & \\
Level & \\
FD & \\
\hline
\end{tabular}

Rejection of the null hypothesis of a unit root is characterized by ** at the $95 \%$ confidence level, and $* * *$ at the $99 \%$ confidence level

In accordance with Figs. 1 and 2, all ADF tests at levels include a trend, whereas those at first differences include a drift term

The optimum lag length for the variables in levels was determined by using the lag associated with the minimum value of the Akaike Information Criterion

The key determinants of final energy use consist of per capita GDP (as a surrogate for income), population, and the end-use level fuel price. Final energy is also determined by the inertia in the energy system, i.e., the speed at which the capital stock is being replaced over time. In addition, non-price induced changes in technology over time can also reduce the demand for final energy.

\subsection{Historical data analysis}

The dependency of final energy use $(F E)$ on its determinants is shown in Eq. 1 for an autoregressive distributed lag model with one lag each for per capita GDP and fuel price.

$$
\begin{aligned}
\ln F E_{t}=\beta_{0} & +\beta_{1} \cdot \ln (G D P / \text { cap })_{t}+\beta_{2} \cdot \ln (G D P / \text { cap })_{t-1}+\beta_{3} \cdot \ln P_{t}+\beta_{4} \cdot \ln P_{t-1} \\
& +\beta_{5} \cdot \ln P_{o p_{t}}+\beta_{6} \cdot \ln F E_{t-1}+\tau \cdot T+\delta \cdot D_{t}+u_{t}
\end{aligned}
$$

Thereby $\beta_{1}$ relates to the short-run income elasticity, $\beta_{2}$ to the current period impact of changes in income during the previous time step (we use GDP, i.e., gross domestic product, as a surrogate for income), $\beta_{3}$ to the short-run fuel price elasticity, $\beta_{4}$ to the impact of changes in the fuel price during the previous time step, $P$ to the weighted average price of all fuels as experienced by the consumer, $\beta_{5}$ to the population elasticity, Pop to the U.S. population, $1-\beta_{6}$ to the speed of adjustment (the lagged term of final energy use therefore represents the inertia in final energy use from 1 year to the next, $\tau$ to the coefficient of the time trend, and $u$ to the error term; subscript $t$ refers to time, i.e., the year of observation. The time trend is introduced to reflect non price-induced changes in technology that affect final energy use.

When estimating the historical evolution of final energy, a dummy variable $D_{t}$ needs to be added to Eq. 1 to account for energy system shocks that affect oil use. The first differences of 
the LHS variable (final energy use) in Fig. 2b suggests that $D_{t}$ could assume the value " 1 " in 1974 (first oil shock), 1980 (second oil shock), 1991 (Gulf war), and 2008 (Global Financial Crisis), as these drastic changes may less likely be picked up by the model. (This hypothesis was tested and partly rejected through examining the t-statistic of each dummy variable when estimating the model).

The single equation error correction model of Eq. 2 is an isomorphic transformation of Eq. 1 that clearly emphasizes the short-run and long-run elasticities and speed of adjustment.

$$
\begin{aligned}
\Delta \ln F E_{t}=\alpha_{0}+\alpha_{1} \cdot \Delta \ln F E_{t-1}+\gamma_{0} \cdot \Delta \ln (G D P / \text { cap })_{t}+\gamma_{1} \cdot \Delta \ln (\text { GDP } / \text { cap })_{t-1}+\gamma_{2} \\
\cdot \Delta \ln (G D P / \text { cap })_{t-2}+\gamma_{3} \cdot \Delta \ln P_{t}+\gamma_{4} \cdot \Delta \ln P_{t-1}+\gamma_{5} \cdot \Delta \ln P_{t-2}+\gamma_{6} \\
\cdot \Delta \ln P o p_{t}+\delta \cdot D_{t}+\tau \cdot T+\phi \cdot\left(\ln F E_{t-1}+\frac{\beta_{1}}{\phi} \cdot \ln (\text { GDP } / \text { cap })_{t-1}+\frac{\beta_{2}}{\phi} \cdot \ln P_{t-1}+\frac{\beta_{3}}{\phi} \cdot \ln P_{o p}\right)+u_{t-1}
\end{aligned}
$$

Equation 2 describes the equilibrium relationship between the first differences of the logarithm in final energy $\left(\ln F E_{t}-\ln F E_{t-1}\right)$ and those of its lagged term along with the first differences of the other right hand side variables from Eq. 1 and the lagged term of their levels. A change in any of the first-differenced (and stationary) right hand side variables causes an immediate change in the first-differenced (and stationary) left hand side variable, as dictated by the respective short-run elasticities $\alpha_{\mathrm{i}}$ and $\gamma_{\mathrm{i}}$. The error correction term then indicates the longterm adjustments of the left hand side to changes in any of the lagged variables. These will be distributed over future time periods according to the rate of error correction or speed of adjustment $\phi$; the long-run elasticities then correspond to $\beta_{i} / \phi$. Hence, a given increase in e.g. GDP/cap will have an immediate short-term impact on final energy use of $\gamma_{0}$ and an accumulated long-term impact of $\beta_{1} / \phi$.

\subsection{Panel data analysis}

Because of the stationary characteristics of the Group 1-4 scenario outputs by both GCAM and REMIND, the intrinsic energy-economy-models' coefficients were estimated with a relationship very similar to Eq. 1, where subscript $i$ is added to represent the $(I=26)$ scenarios. The dummy variable was dropped, as the temporal occurrence of shocks is impossible to predict. The resulting panel data model is given by Eq. 3 .

$$
\ln F E_{i, t}=C+\alpha \cdot \ln (G D P / c a p)_{i, t}+\beta \cdot \ln P_{i, t}+\gamma \cdot \ln P o p_{i, t}+\tau \cdot T+\lambda \cdot \ln F E_{i, t-1}+u_{i, t}
$$

Note that the 2010-2050 data used to estimate Eq. 3 are reported in 5-year intervals, whereas Eq. 2 can be estimated with annual observations.

\section{Model estimation}

\subsection{Historical data analysis}

Before estimating the model described by Eq. 2, the time trend was split into three different periods. The historical development of final energy intensity (final energy use per passenger$\mathrm{km}$ ) for U.S. passenger travel shows a roughly constant development from 1950 to 1964 , followed by a slight increase through 1978, and a subsequent decline through 2010 (Schäfer 2013). In freight transportation, energy intensity (final energy use per revenue tonne-km) has declined between 1950 and 1957 but remained roughly constant thereafter (Schäfer 2013). 
Taking these developments into account, an additional time trend was introduced in 1957 and another one in 1979 into Eq. 2 using dummy variables. Manual iteration for maximum $\mathrm{R}^{2}$ suggested that the first additional time trend should already be introduced in 1954 but confirmed the 1979 introduction of the second trend.

Equation 2 was estimated with ordinary least squares for the entire 1950-2010 data series; the results are shown in Table 2. All signs are consistent with economic theory and all coefficient estimates with the exception of the long-run multiplier of population are statistically significant at least at the $95 \%$ confidence level. The adjusted $\mathrm{R}^{2}$ results in around 0.90 . The residuals seem to have white noise properties (normality test) and there is no evidence of serial correlation (Portmanteau Q test).

The short-run income elasticity of around 0.6 is slightly mitigated at any subsequent time step $t+1$ and $t+2$, but remains positive overall. The short-run fuel price elasticity is around -0.08 . Among the dummy variables, only those associated with 1974,1980 , and 1991 turn out to be significant. Jointly, the three time trends roughly reproduce the energy intensity trends

Table 2 Parameter estimates, t-statistics (in parenthesis), and regression statistics for Eq. 2 (historical data) using annual data from 1950 to 2010

\begin{tabular}{|c|c|}
\hline No. observations & 58 \\
\hline$\alpha_{0}$ (Constant) & $8.804(2.28)$ \\
\hline$\gamma_{0}$ (Short-run elasticity: GDP/cap) & $0.590(8.80)$ \\
\hline$\gamma_{1}$ (L1 short-run elasticity: GDP/cap) & $-0.175(-2.62)$ \\
\hline$\gamma_{2}$ (L2 short-run elasticity: GDP/cap) & $-0.151(-2.39)$ \\
\hline$\gamma_{3}$ (Short-run elasticity: fuel price) & $-0.081(-6.86)$ \\
\hline$\delta 1974$ (Dummy variable) & $-0.043(-4.13)$ \\
\hline$\delta 1980$ (Dummy variable) & $-0.021(-2.04)$ \\
\hline$\delta 1991$ (Dummy variable) & $-0.026(-2.88)$ \\
\hline$\tau$ (Time) & $-0.006(-2.33)$ \\
\hline$\tau 1955$ (Time) & $0.00001(2.37)$ \\
\hline$\tau 1979$ (Time) & $-0.00002(-6.26)$ \\
\hline$\phi$ (Speed of error correction) & $-0.078(-2.87)$ \\
\hline$\beta_{1}$ (Long-term effect: GDP/cap) & $0.246(3.27)$ \\
\hline$\beta_{2}$ (Long-term effect: fuel price) & $-0.026(-3.64)$ \\
\hline$\beta_{3}$ (Long-term effect: population) & $0.267(1.54)$ \\
\hline \multicolumn{2}{|l|}{ Test statistics } \\
\hline Adjusted $\mathrm{R}^{2}$ & 0.9023 \\
\hline Root MSE & 0.0084 \\
\hline Portmanteau Q test for 27 lags, $p$-value & 0.9774 \\
\hline Normality test (Shapiro-Wilk), $p$-value & 0.2820 \\
\hline \multicolumn{2}{|l|}{ Implied long-run elasticities $\left(\beta_{\mathrm{i}} / \phi\right)$} \\
\hline GDP/cap & $3.134(4.87)$ \\
\hline Fuel price & $-0.328(-2.02)$ \\
\hline Population & $3.401(2.20)$ \\
\hline
\end{tabular}

The null hypothesis of the Portmanteau Q test for white noise is no serial correlation up to order (here) 27; the large $p$-value of $98 \%$ suggests that the null-hypothesis cannot be rejected. The null hypothesis of the ShapiroWilk test is that the residuals are normally distributed; the large $p$-value of $28 \%$ suggests that the null-hypothesis cannot be rejected 
described above, i.e., a long-term decline by around $0.6 \%$ per year with a slightly lower intermediate (1955-1978) reduction.

The rate of error correction $\phi$ suggests that around $8 \%$ of the remaining deviation from equilibrium has been corrected in each subsequent year in response to any change in per person GDP, fuel price, and population. The resulting long-term effects include an income elasticity of around 3.1, with a $95 \%$ confidence interval ranging from 1.8 to 4.4 . This elasticity accounts for the increase in passenger and freight transportation with rising income, the shift towards larger and more energy intensive vehicles in passenger travel and the mode shift towards (more energy intensive) trucks in freight transportation, along with the rising relative importance of air travel in intercity transportation. Our estimated income elasticity is substantially higher than the values found in the literature for road transportation (mainly automobiles). Based on a review of around 50 studies, Goodwin et al. (2004) derive an income elasticity of 1.08 (standard deviation of 0.35 ). The long-run fuel price elasticity turns out to be an inelastic -0.33 and compares well with the gasoline long-run price elasticities of -0.31 and -0.38 for light-duty vehicles, estimated by Small and Van Dender (2007) using 1997-2001 data and 1966-2001 data, respectively. In addition, the associated $95 \%$ confidence interval stretches from -0.66 to 0 and is also consistent with other estimates of long-run fuel price elasticities for passenger travel (see, e.g., Oum et al. 1990; Goodwin et al. 2004). Finally, the long-run population elasticity turns out to be 3.4. Intuition suggests that this value should be around unity: an extra person per household would most likely result in a less than proportional increase in transportation energy use as some of the additional trips are likely to be shared trips, while an extra household could lead to a roughly proportional increase in transportation energy use - an elasticity of around one. However, the lower end of the $95 \%$ confidence interval is as small as 0.29 and the confidence interval thus includes a range of all plausible values.

\subsection{Panel data analysis}

Several estimation challenges exist with respect to the dynamic panel data model in Eq. 3. The error term $u_{i, t}$ can be decomposed into unobserved individual level effects (that are independent of time) and observation specific errors. First-differencing Eq. 3 then removes the unobserved individual level effects, and therefore eliminates the omitted variable bias in the model estimation. However, differencing the predetermined variables $F_{i, t-1}$ makes them endogenous because the first differenced observation specific errors are correlated with the firstdifferenced $F_{i, t-1}$, thus violating the requirement for strict exogeneity. Ordinary least squares estimators would thus be biased. Therefore we use the estimator developed by Arellano and Bond (1991) that is derived from the Generalized Method of Moments and instruments those differenced variables that are not strictly exogenous with their available lags.

Table 3 summarizes the regression results of the panel data models, which were estimated with 2010-2050 data from all Groups 1-4. The sign of all coefficients is consistent with economic theory and all coefficients are highly significant. The null hypothesis of the Wald statistic (all coefficients except the constant are zero) is clearly rejected. For comparison, the long-run results estimated from Eq. 2 based on the entire time horizon 1950-2010 data are also shown.

The elasticity of the lagged dependent variable $(\lambda)$ of GCAM and REMIND over a 5-year period results in 0.542 and 0.504 , respectively. Although both coefficients are slightly lower than that implied in the annual historical (1950-2010) dataset over 5 years of $(1-0.078)^{5}=$ 0.666 , thus suggesting a slightly smaller inertia compared to that observed historically, they are still within the confidence interval of the latter. The roughly comparable inertia and thus speed 
Table 3 Parameter estimates, z-statistic (in parenthesis), and regression statistics for Eq. 3 (dynamic panel data) compared with key results from Table 2 (with t-statistics in parenthesis)

\begin{tabular}{llll}
\hline & GCAM 2010-2050 & REMIND 2010-2050 & Historical 1950-2010 \\
\hline No. Observations & 182 & 182 & 58 \\
Freq. of observations (years) & 5 & 5 & 1 \\
$\alpha_{0}$ (Constant) & $6.730(14.21)$ & $3.058(5.35)$ & $8.804(2.28)$ \\
$\alpha$ (Income elasticity) & $0.158(9.58)$ & $0.300(11.64)$ & $0.590^{(1)}(8.80)$ \\
$\beta$ (Fuel price elasticity) & $-0.125(-8.55)$ & $-0.257(-16.99)$ & $-0.082(-6.86)$ \\
$\gamma$ (Population elasticity) & $0.644(16.15)$ & $0.674(13.70)$ & 0 \\
$\tau$ (Time, in \%/yr) & $-0.005(-14.80)$ & $-0.004(-7.87)$ & $-0.006(-2.33)$ \\
$\lambda$ (Elasticity of lagged dependent variable) & $0.542(9.94)$ & $0.504(9.89)$ & \\
$\phi$ (Error correction rate) & & & $-0.078^{(2)}(-2.87)$ \\
Implied long-run & & & \\
$\quad \alpha$ (Income elasticity) & $0.345(12.28)$ & $0.606(11.71)$ & $3.134(4.87)$ \\
$\beta$ (Fuel price elasticity) & $-0.272(-12.16)$ & $-0.519(15.64)$ & $-0.327(-2.02)$ \\
$\gamma$ (Population elasticity) & $1.405(12.73)$ & $1.360(7.61)$ & $3.401(2.20)$ \\
Test statistics & & & 0.9023 \\
$\quad \mathrm{R}^{2}$ & & 3682.4 & \\
$\quad$ Wald $\chi^{2}$ & 3492.3 & & \\
\hline R & & &
\end{tabular}

Both dynamic panel data models were estimated with the Arellano-Bond estimator

The reported Error Correction Model (ECM) coefficients are long-run elasticities

(1) At time t only; see Table 2 for those at $\mathrm{t}-1$ and $\mathrm{t}-2$

(2) After 5 years, the implied elasticity of the lagged dependent variable would result in $(1-0.078)^{5}=0.666$

of error correction of the model outputs to those underlying the historical data accumulated over 5 years would imply comparing the long-run elasticities of the annual historical data to the short-run elasticities of the panel data model. However, because the long-run elasticities reflect the consumer and industry responsiveness in transportation energy use to changes in any of the RHS variables to have fully materialized, we also compare these estimates for both the historical and the projected data.

The intrinsic short- and long-run income elasticities of both energy-economy-models are significantly smaller than that observed historically, a fact we already observed when comparing the historical increase in final energy use to the projected levels of GCAM and REMIND in Fig. 1a. As already suspected from Fig. 1a, the income elasticity of REMIND (0.300[short-run: SR], 0.606[long-run: LR]) is larger than that of GCAM $(0.158[\mathrm{SR}]$, $0.345[\mathrm{LR}])$.

In contrast, the intrinsic short- and long-run price elasticities of both energy-economymodels are within the $95 \%$ confidence interval of the long-run elasticity (of - 0.327 ) estimated using the 1950-2010 time series. Thereby, the intrinsic price elasticity of the REMIND model $(-0.257[\mathrm{SR}],-0.519[\mathrm{LR}])$ turns out to be larger than that of GCAM $(-0.125$ [SR], $-0.272[\mathrm{LR}])$. The intrinsic short- and long-run population elasticities of GCAM and REMIND are also plausible and within the confidence interval of the rather large estimate of the historical data.

The estimated time coefficient of around $0.5 \%$ autonomous reduction of final energy use per year $(0.5 \%$ for GCAM and $0.4 \%$ for REMIND) is slightly smaller than those estimated over the historical time period of $0.6 \%$ per annum but well within the confidence interval of 
the latter. (For GCAM, the estimated autonomous reduction of final energy use of $0.5 \%$ per year is identical to the exogenously imposed autonomous reduction of final energy intensity; similarly, the inputs into the production functions underlying the REMIND model are reduced by scaling factors that change over time and the weighted average of these scaling factors results in our estimated $0.4 \%$ decline in transportation sector final energy use). Between the two energy models, price elasticity and autonomous improvements seem to trade. Reductions of final energy use result to a larger extent from non-price induced changes in GCAM and due to a larger sensitivity to price changes in REMIND.

Figure 3 compares the $95 \%$ confidence intervals of the estimated long-run elasticities from the 1950-2010 historical development and the short- and long-run coefficients from both GCAM and REMIND. In addition, literature survey-based $95 \%$ confidence intervals related to road transportation (mainly automobiles) are shown, which also include other countries than the U.S. (Goodwin et al. 2004). As can be seen, the short- and long-run elasticity-based confidence intervals of the two energy-economy-models overlap with all those underlying the historical development and the literature survey-based studies, except for the income elasticity. There, the short-run elasticities of GCAM and REMIND are outside the $95 \%$ confidence intervals of both the literature survey-based study and our historical estimate. However, these models' intrinsic long-run elasticities still overlap with the confidence interval of the literature-based study, which itself is not within the confidence interval of our own estimate using the historical U.S. data. This apparent inconsistency may suggest that our own estimate of the long-run income elasticity with respect to final energy is at the higher end.

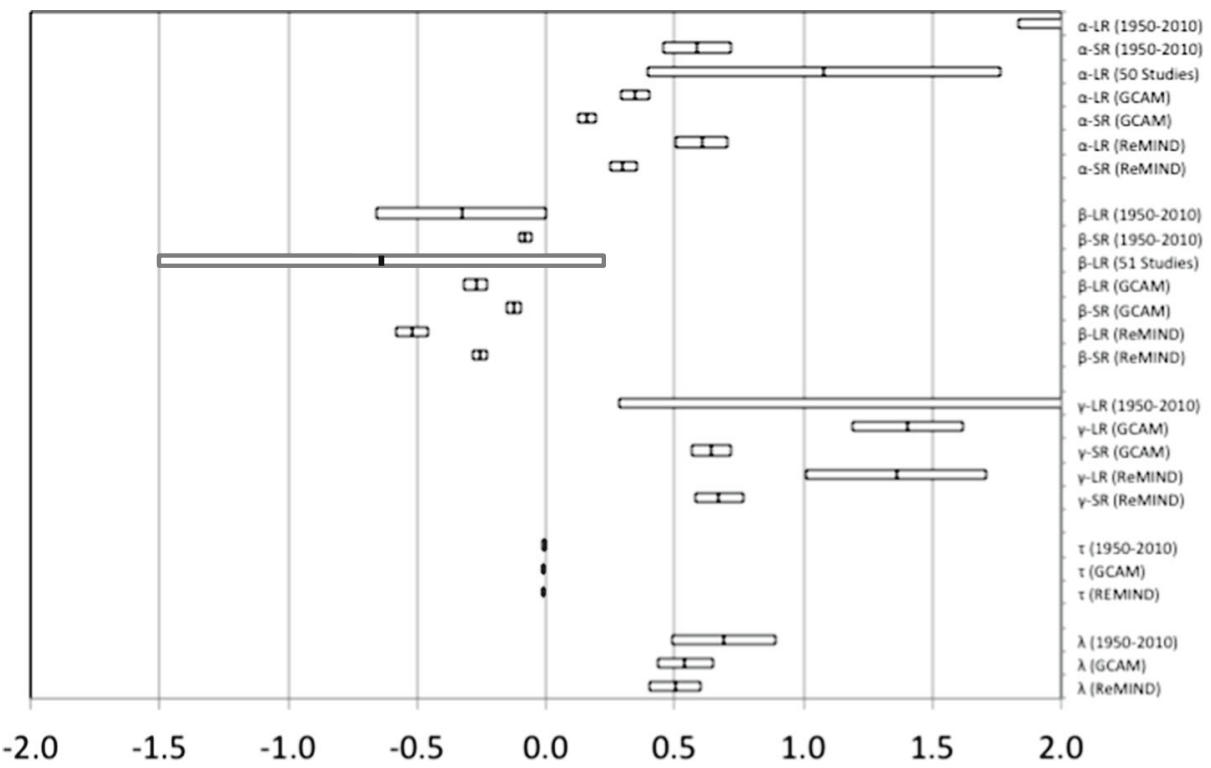

Fig. 3 Ninety five percent confidence intervals of the coefficient estimates: income elasticity $(\alpha)$, fuel price elasticity $(\beta)$, population elasticity $(\gamma)$, the time trend $(\tau)$, and coefficient of lagged dependent variable $(\lambda)$. The source for the literature-survey based intervals (around 50 studies) is Goodwin et al. (2004). SR: short-run; LR: long-run 


\section{Interpretation of the results}

The most striking difference between the estimated intrinsic elasticities of the GCAM and REMIND models and the historical development is the comparatively small intrinsic income elasticity of both models. (In light of the recently introduced tight fuel economy standards for light-duty vehicles, such lower income elasticity of fuel use seems plausible; however, as described below, both models did not include these new tight regulations and therefore we examine this discrepancy in more detail). In addition, the REMIND model incorporates a slightly larger price elasticity than GCAM. Here we attempt to interpret these differences through the key assumptions and characteristics underlying each energy-economy-model.

\subsection{Income elasticity}

In GCAM, the transportation sector is implemented on the service level (passenger-kilometers traveled and tonne-kilometers generated) and driven by exogenous, scenario-specific growth in population and GDP, and endogenous generalized transportation costs (Kyle and Kim 2011); the latter are expressed as travel money expenditures plus the ratio of the value of time (as a percentage of the wage rate) and average travel speed. For the 26 scenarios examined, passenger-kilometers traveled and tonne-kilometers generated double at most, with the exception of one freight transport projection in one of the baseline (Group 1) scenarios. The comparatively modest projected growth in passenger travel partly results from the assumed high value of time, being $100 \%$ of the wage rate. The time cost component of the generalized cost term then corresponds to the ratio of wage rate and average travel speed. As the wage rate continues to rise with per person GDP at a higher rate than the average speed, travel costs increase and therefore depress travel demand. A lower value of time would reduce the significance of the time cost term compared to the economic cost component and therefore result in a stronger growth in passenger transportation demand.

Another GCAM-related important reason for the comparatively low income elasticity with respect to final energy use is a modestly stringent CAFE standard, tightening average lightduty vehicle fuel economy levels from a stock average of about 20 miles per gallon (MPG) in 2005 to 24 MPG in 2020 and 26 MPG in 2035.

The transport sector of REMIND is the hybrid of a linear energy systems model and a macroeconomic production function. The linear energy systems model converts final energy inputs into energy services (mobility) for competing transportation modes, using vehiclespecific efficiencies and capital costs. At the same time, each mode represents an input factor to the constant elasticity of substitution (CES) production function representing the total mobility produced. The ability for mode substitution is determined by a substitution elasticity of 1.5. The total "value of transport" is then input into a rather inflexible CES nest (substitution elasticity of 0.3 ) and substitutes with stationary energy use to produce an "aggregate energy" good that itself is input to the topmost CES-function combining capital, labor and the aggregate energy good to produce GDP (Luderer et al. 2013). The individual inputs into the nested CES production function have time-dependent CES-efficiency parameters, leading to a time-dependent reduction of final energy demand. Thereby the efficiency parameters are calibrated in such a way that the model in standard configuration reproduces an external baseline scenario (Pietzcker et al. 2014).

The assumptions underlying the baseline scenario and its implementation are a major factor affecting the comparatively low income elasticity of transport sector final energy use for the U.S. in REMIND. Historical per-capita transport final energy use levels in the U.S. are higher by a factor of 2-3 compared to those seen in most other parts of the world at similar per-capita 
income levels. The REMIND baseline scenario assumes that the future U.S. development will partially converge to other regions because of a number of factors, including i) a change in the expectations about future oil prices, leading to a renewed effort to decrease oil demand from transport; ii) increased development and use of high-efficiency vehicles driven by stringent efficiency standards implemented both abroad and in the U.S.; iii) congestion effects in metropolitan areas limiting further mobility growth, and iv) increased public transport infrastructure and stronger city planning, reducing the ultimate dependence on light-duty vehicles. This assumed international convergence underlying the REMIND model entails a slow reduction of per-capita transport energy demand in the U.S., which in combination with the assumed continued GDP growth leads to the described low implicit income elasticity.

\subsection{Price elasticity}

The intrinsic price elasticity in GCAM is determined by the assumed price elasticities of the energy service demands, and by the model's ability to substitute more fuel-efficient transportation modes and technologies for existing ones. In the passenger transport sector, future mode shares are determined primarily by the income-driven value of time, and as such tend to be comparatively less responsive to changes in energy prices. In contrast, REMIND simulates a stronger responsiveness to changes in fuel prices because the value of time is not explicitly included in the determination of demand for transportation. Accordingly, fuel costs make up a larger share of total travel costs, and a change of fuel costs thereby leads to a larger change of total travel costs compared to GCAM. This effect, in combination with the possibility of i) substituting modes for one another (see discussion in the income elasticity section above) and ii) reducing the demand for transport energy services in the "aggregated energy" CES nest as the relative price of mobility increases, leads to the observed responsiveness to fuel prices in REMIND. In both models, the adoption of fuel-saving and alternative fuel technologies depends on the specified set of alternative technologies that becomes available over time, and constraints that limit the rate of penetration of and thus substitution for existing technologies. These are also important assumptions that can strongly affect the price elasticity and would need to be studied carefully.

\section{Conclusions}

This paper presented an econometric approach to validating energy-economy-models, namely using a large number of model scenario outputs to estimate aggregate price- and income elasticities with the help of linear dynamic panel data models. We compared these models' intrinsic elasticities with one another and those based on historical data.

Both energy-economy-models behave broadly similar with respect to transportation final energy use. They also compare well to the elasticities associated with the long-term historical development of the U.S. transportation sector and a survey of around 50 studies from various countries, thus generating confidence in the way the models behave. The only noticeable difference to historical observations and those from other studies is their comparatively low income elasticity.

The lower responsiveness of final energy use with respect to changes in income can be explained mainly by assumptions underlying each of the energy-economy-models, namely the rising importance of the value of time for transport decisions in GCAM, and the assumed deceleration of transport energy demand growth in REMIND due to fuel efficiency standards, congestion effects, and improved city planning and public transport infrastructure. Because 
such differences in income elasticity to the historical value can lead to widely different levels in final energy use and $\mathrm{CO}_{2}$ emissions, especially over the very long (close to 100 years) time horizon that underlies such energy-economy-models, the need for a careful evaluation of some of these assumptions becomes apparent.

The approach pursued here can be applied to more variables of the transportation sector. Estimating $\mathrm{CO}_{2}$ emissions as a function of primary energy use, carbon prices, etc. would be a logical next step. In addition, this approach could be extended to more sectors and ultimately entire energy-economy-models.

Open Access This article is distributed under the terms of the Creative Commons Attribution License which permits any use, distribution, and reproduction in any medium, provided the original author(s) and the source are credited.

\section{References}

Arellano M, Bond S (1991) Some tests of specification for panel data: Monte-Carlo evidence and an application to employment equations. Rev Econ Stud 58:277-297

Beckman J, Hertel T, Tyner W (2011) Validating energy-oriented CGE models. Energy Econ 33:799-806

Energy Modeling Forum (EMF) (1977) Energy and the Economy, EMF Report 1, Volume 1, September 1977, Stanford, CA. http://emf.stanford.edu/files/pubs/22407/1v1.pdf

Goodwin P, Dargay J, Hanly M (2004) Elasticities of road traffic and fuel consumption with respect to price and income: a review. Transp Rev 24:275-292

Kriegler E, Mouratiadou I, Brecha RJ, Calvin K, De Cian E, Edmonds J, Kejun J, Luderer G, Tavoni M, Edenhofer $\mathrm{O}$ (this issue) Will economic growth and fossil fuel scarcity help or hinder climate stabilization? Overview of the RoSE multi-model study. Climatic Change.

Kyle P, Kim SH (2011) Long-term implications of alternative light-duty vehicle technologies for global greenhouse gas emissions and primary energy demands. Energy Policy 39:3012-3024

Luderer G et al (2013) Description of the REMIND Model (Version 1.5). http://www.pik-potsdam.de/research/ sustainable-solutions/models/remind/description-of-remind-v1.5

Oum TH, Waters WG, Yong JS (1990) A survey of recent estimates of price elasticities of demand for transport. The World Bank, Infrastructure and Urban Development Department

Pietzcker RC, Longden T, Chen W, Fu S, Kriegler E, Kyle P, Luderer G (2014) Long-term transport energy demand and climate policy: alternative visions on transport decarbonization in energy-economy models. Energy 64:95-108

Schäfer A (2013) Transportation demand, technological change, and energy use in the U.S. transportation sector since 1900. Draft paper. Precourt Energy Efficiency Center, Stanford University

Schäfer A, Heywood JB, Jacoby HD, Waitz IA (2009) Transportation in a climate-constrained world. The MIT Press, Cambridge

Schwanitz VJ (2013) Evaluating integrated assessment models of global climate change. Environ Model Softw 50:120-131

Small KA, Van Dender K (2007) Fuel efficiency and motor vehicle travel: the declining rebound effect. Energy J 28(1):25-51

Wilson C, Grübler A, Bauer N, Krey V, Riahi K (2013) Future capacity growth of energy technologies: are scenarios consistent with historical evidence? Clim Chang 118:381-395 